\title{
EFFECTS OF NICOTINE AND TYRAMINE ON CONTRACTILE ACTIVITY OF THE COLON $*, * *$
}

\author{
N.W. WEISBRODT ***, C.C. HUG, Jr., S.K. SCHMIEGE \\ and P. BASS \\ Department of Pharmacology, University of Michigan \\ Medical School and Parke, Davis \& Co., Medical and \\ Scientific Affairs Division, Ann Arbor, Michigan 48104, USA
}

Received 11 February 1970

Accepted 16 July 1970

\begin{abstract}
N.W. WEISBRODT, C.C. HUG, Jr., S.K. SCHMIEGE and P. BASS, Effects of nicotine and tyramine on contractile activity of the colon, European J. Pharmacol. 12 (1970) 310-319.

Contractile activity of the descending colon of the anesthetized dog was monitored with strain gage force transducers. Nicotine and tyramine caused primarily a relaxation of the circular and longitudinal muscle. A secondary stimulation frequently followed the inhibition. Adrenalectomy partially antagonized the effects of nicotine. Xylocholine and reserpine petreatment reduced the early portion of the inhibitory response to nicotine. Hexamethonium or a combination of adrenalectomy with either xylocholine or reserpine pretreatment abolished the effects of nicotine. The effects of tyramine were antagonized by cocaine and reserpine-pretreatment. Tolazoline and propranolol (in combination) reduced the effects of both nicotine and tyramine. We conclude that both nicotine and tyramine relaxed the colon by releasing catecholamines. Nicotine caused release from the adrenal glands and adrenergic nerve endings; tyramine produced release from the adrenergic nerve endings.
\end{abstract}

$\begin{array}{lll}\text { Nicotine } & \text { Catecholamines } & \text { Colonic motility } \\ \text { Tyramine } & \text { Gastrointestinal tract } & \text { Strain gage force transducers }\end{array}$

\section{INTRODUCTION}

Smokers commonly experience symptoms which are related to altered activity of the large intestine. For example, Schnedorf and Ivy (1939) reported that, in healthy human volunteers, smoking was

* The study was supported by a grant from the American Medical Association, Education and Research Foundation. It represents a portion of a doctoral dissertation by N.W. Weisbrodt.

** Please request reprints from: Dr. Carl C. Hug, Jr., Department of Pharmacology, University of Michigan, M6420 Medical Science Bldg., Ann Arbor, Michigan 48104.

*** Present address: Gastroenterology Research Laboratory, Department of Internal Medicine, University of Iowa College of Medicine, lowa City, Iowa 52240. associated with 'increased propulsive activity' of the colon.

Nicotine, the principle alkaloid contained in tobacco, is usually implicated as the agent responsible for the acute biological effects of tobacco (Larson et al., 1961). Nicotine definitely alters the contractile activity of the gastrointestinal tract, but its effects have not been fully characterized. It is generally believed that nicotine stimulates peristalsis (Volle and Koelle, 1970; Smoking and Health, 1964). This conclusion is based mainly on observations made on isolated segments of smooth muscle taken from the upper gastrointestinal tract. However, this conclusion is not valid for the effects of systemically administered nicotine in the intact animal. As early as 1899, Bayliss and Starling demonstrated that nicotine administered intravenously caused inhibition of 
canine small intestinal activity, an observation which has been confirmed repeatedly (Houssay and Molinelli, 1926; Mulinos, 1927-28; Hamet, 1930; Carlson et al., 1970a). To our knowledge, no study of the effects of nicotine on the colon has been reported.

The inhibitory effects of nicotine on contractile activity have been attributed to the release of catecholamines from the adrenal glands (Houssay and Molinelli, 1926; Carlson et al., 1970b) and from peripheral adrenergic nerves (Carlson et al., 1970b).

The purposes of this study were: 1) to determine the effects of nicotine on the contractile activity of the descending colon of the anesthetized dog, and 2) to determine the mechanism(s) of action of nicotine in producing its effects.

\section{METHODS}

\subsection{Animal preparation}

Seventy-one mongrel dogs of either sex and weighing between 7.2 and $17.5 \mathrm{~kg}$ were used. The animals were anesthetized with a mixture of allobarbital, $60 \mathrm{mg} / \mathrm{kg}$, urethane, $240 \mathrm{mg} / \mathrm{kg}$, and monoethylurea, $240 \mathrm{mg} / \mathrm{kg}$ (Dial with Urethane Solution, Ciba Pharmaceutical Co.). Drugs were administered through a silicone elastic catheter inserted into the right external jugular vein with the tip near the right atrium. Femoral arterial blood pressure was monitored with a Statham pressure transducer. Body temperature was maintained at approximately $37^{\circ} \mathrm{C}$ and, when necessary, respiration was maintained by a Harvard respirator.

Extraluminal strain gage force displacement transducers were used to monitor contractile activity (Jacoby et al., 1963; Carlson, 1969). These transducers offer the following advantages: 1) the units are sutured on the serosal surface of the colon and thus do not impede the flow of intraluminal contents and do not stimulate mucosal receptors; 2) the units record contractile activity of the smooth muscle directly; 3) the units monitor separately the activity of the circular and longitudinal muscle layers of the colon. Four force transducers were sutured to the serosal surface of the colon; two on the cranial descending colon and two on the caudal descending colon, 14 and $4 \mathrm{~cm}$ respectively from the pelvic floor muscles. At each site, one transducer monitored longitudinal muscle activity and the other monitored circular muscle activity.

\subsection{Data analysis}

Quantitative analysis of the data was done by linear displacement analysis with a device normally used to determine distances on road-maps (Callantine et al., 1967, 1969; Behrman and Burchfield, 1968). The myogram from each transducer was measured and the length of the base line for the same time period was subtracted. This number (inches) was then divided by the time period (minutes) to express the level of activity. For each injection of an agonist, the time period beginning $10 \mathrm{~min}$ before the injection was analyzed as control. The $10 \mathrm{~min}$ period following injection was divided into five periods of two min each. The activity in each post-drug period was determined and expressed as percent of control. Statistical significance of drug-induced alterations in contractile activity was determined by using Student's $t$ test.

\subsection{Drug administration}

Nicotine and tyramine were injected into the jugular vein by introducing the drug solution $(<2 \mathrm{ml})$ into the catheter (volume $>2.5 \mathrm{ml}$ ) and then operating the infusion pump for one min at a rate of $3.0 \mathrm{ml} / \mathrm{min}$. This procedure avoided variation in drug responses due to variation in rate of administration.

Intravenous infusions of other drugs were made at the following rates: $(\mu \mathrm{g} / \mathrm{kg} / \mathrm{min})$ : 1-norepinephrine and d,l-isoproterenol 2; hexamethonium and xylocholine 200; cocaine 300; tolazoline 400; and propranolol 80 . The rates of administration of the antagonists were chosen to minimize their effects on blood pressure and spontaneous colonic contractile activity. The total doses of these agents (expressed as base) are presented in the results.

The following sequence was used in animals which were adrenalectomized: 1) initial surgical preparation (see Animal preparation above); 2) thirty minutes after completing the initial surgical preparation the responses to nicotine and tyramine were measured; 3) then bilateral adrenalectomy was performed via a retroperitoneal approach with ligation of the adrenal blood supply and excision of the glands; 4) sixty minutes later the responses to nicotine and tyramine were observed. 
Reserpine-pretreated animals were injected intramuscularly with reserpine, $0.1 \mathrm{mg} / \mathrm{kg} / \mathrm{day}$ on two consecutive days. Approximately $24 \mathrm{hr}$ after the second injection, the animals were anesthetized with 75 percent of the usual anesthetic dose (see above).

\section{RESULTS}

\subsection{Colonic activity in anesthetized dogs}

The spontaneous contractile activity of the canine colon exhibited the following characteristics (see figs. 1 and 2): 1) the activity of the circular and longitudinal layers was of variable frequency and consisted of wave forms of various amplitudes and durations. The longitudinal muscle of the cranial descending colon exhibited the least variability in frequency and wave form; 2) the activity of the cranial descending colon was more persistent than that of the caudal descending colon; 3 ) the amplitude and amount of activity of the longitudinal muscle layers was usually greater than that of the circular muscle layers; 4) there was no apparent coordination of the activity of the two sites.

\subsection{Effects of nicotine, tyramine, norepinephrine,} and isoproterenol

Nicotine, $100 \mu \mathrm{g} / \mathrm{kg}$, inhibited spontaneous activity of both muscle layers of the cranial descending colon in all fifty-one of the animals studied (fig. 1A). The inhibition lasted approximately $6 \mathrm{~min}$ and often was followed by a brief stimulation of activity. The caudal descending colon responded differently. In approximately 80 percent of the animals, nicotine

A

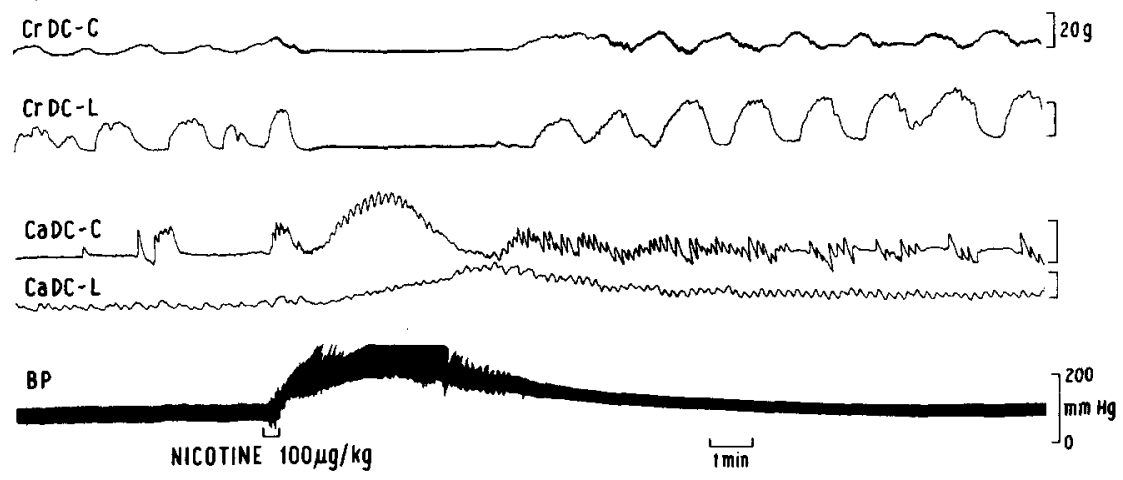

$B$

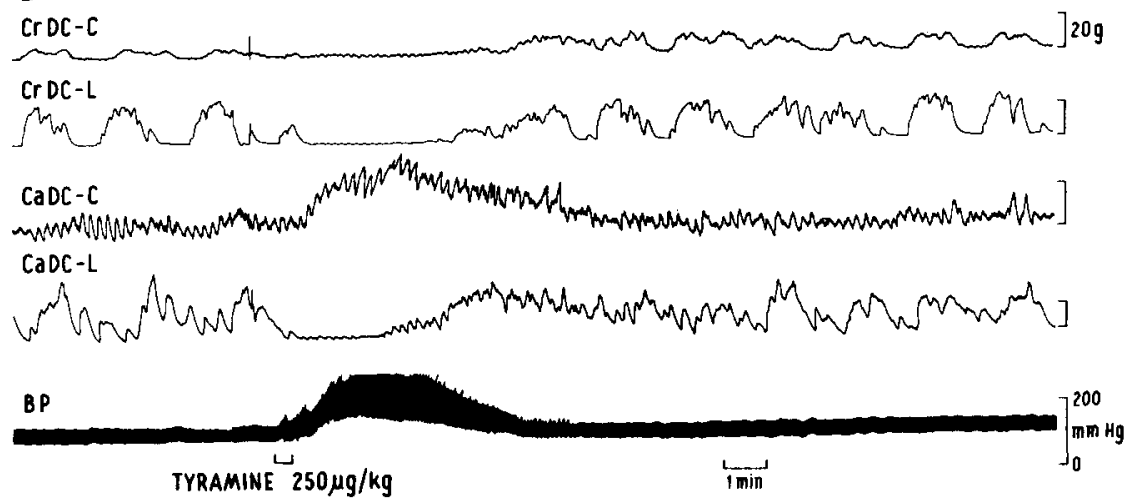

Fig. 1. The effects of in travenously administered nicotine, $100 \mu \mathrm{g} / \mathrm{kg}$ (A), and tyramine, $250 \mu \mathrm{g} / \mathrm{kg}$ (B) on contractile activity of the colon. CrDC-C, cranial-descending circular muscle; CrDC-L, the cranial-descending longitudinal muscle; CaDC-C, caudaldescending circular muscle; CaDC-L, caudal-descending longitudinal muscle; BP, femoral arterial blood pressure. Time periods of drug injection are indicated by the horizontal bars. 


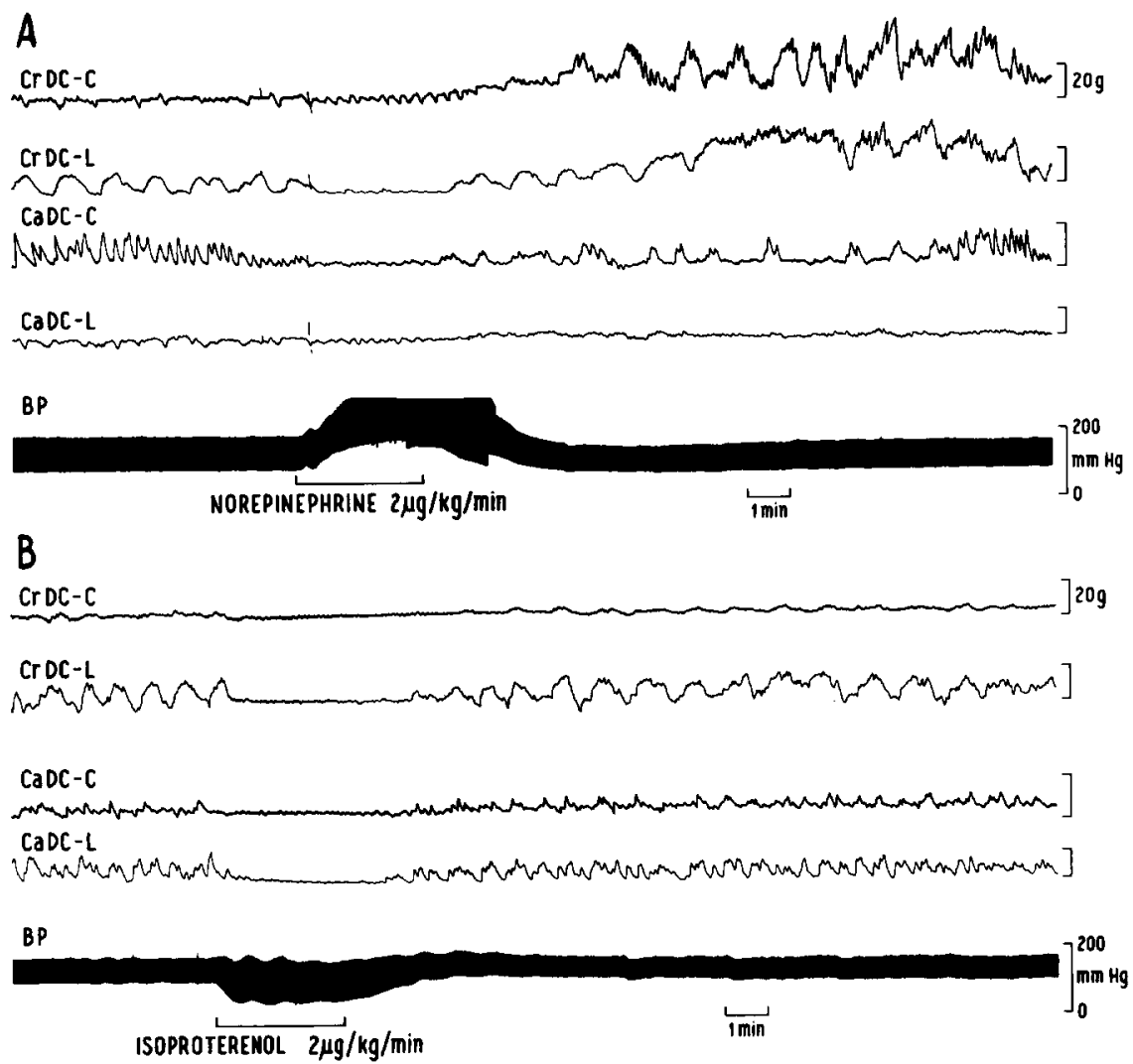

Fig. 2. The effects of intravenously administered norepinephrine, $2 \mu \mathrm{g} / \mathrm{kg} / \mathrm{min}$ (A), and isoproterenol, $2 \mu \mathrm{g} / \mathrm{kg} / \mathrm{min}$ (B). Abbreviations are the same as in fig. 1.

elicited a large contraction of the circular muscle which lasted for several minutes. This was followed by a relaxation and return of spontaneous activity. The longitudinal muscle of the caudal descending colon exhibited decreased spontaneous activity during contraction of the circular muscle. The responses to tyramine, $250 \mu \mathrm{g} / \mathrm{kg}$ (fig. 1B) were essentially the same as the responses to nicotine.

Infusion of either norepinephrine or isoproterenol resulted in cessation of spontaneous activity at all sites (fig. 2). Activity returned when the infusion was terminated. A secondary stimulation was observed in 2 of 5 animals given norepinephrine (fig. 2A).

Since the longitudinal muscle layer of the cranial descending colon exhibited the most regular activity, this site was chosen for detailed quantitative analysis. Nicotine $(25,50$ and $100 \mu \mathrm{g} / \mathrm{kg})$ elicited a dosedependent inhibition of contractile activity (fig. 3, untreated animals). The inhibition was followed by varying degrees of stimulation. In several animals a dose of $10 \mu \mathrm{g} / \mathrm{kg}$ elicited no effect; nicotine, $250 \mu \mathrm{g} / \mathrm{kg}$, produced responses essentially the same as those seen after $100 \mu \mathrm{g} / \mathrm{kg}$. The responses to tyramine, $250 \mu \mathrm{g} / \mathrm{kg}$, were similar to those following nicotine, $100 \mu \mathrm{g} / \mathrm{kg}$ (fig. 3).

\subsection{Modification of the effects of nicotine and tyramine}

3.3.1. Hexamethonium and cocaine

Hexamethonium, $5 \mathrm{mg} / \mathrm{kg}$, completely blocked the effects of nicotine, $100 \mu \mathrm{g} / \mathrm{kg}$, but did not prevent the inhibition by tyramine, $250 \mu \mathrm{g} / \mathrm{kg}$ (fig. 4). In contrast, cocaine, $5 \mathrm{mg} / \mathrm{kg}$, abolished the responses to tyramine but did not block the effects of nicotine (fig. 4). The apparent potentiation by cocaine of both the inhibition and the secondary stimulation to nicotine was not statistically significant. 

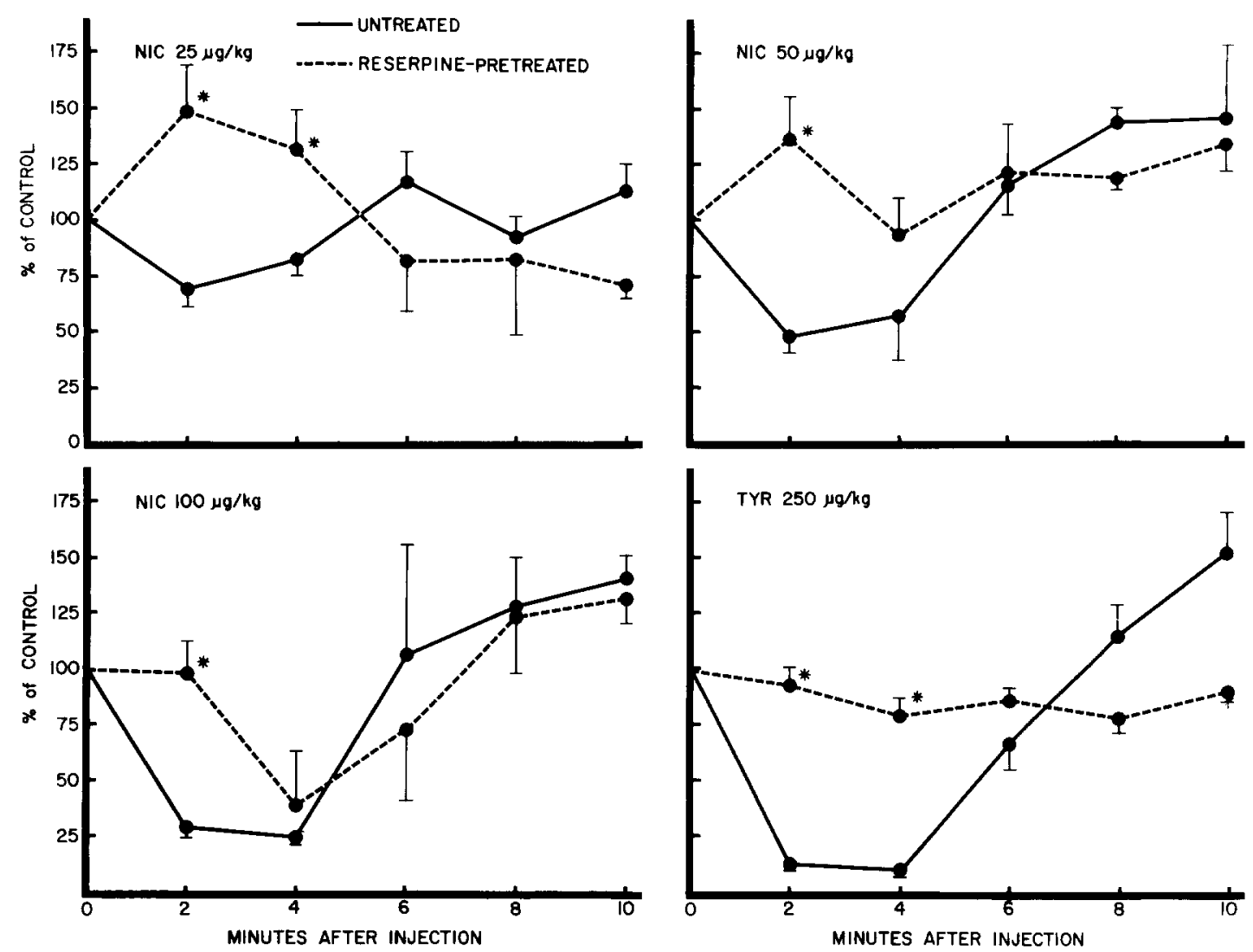

Fig. 3. The effects of nicotine (NIC) and tyramine (TYR) on contractile activity of cranial descending longitudinal muscle of the colon (CrDC-L). Each of eight untreated animals and each of three reserpine-pretreated animals received nicotine (25, 50 and $100 \mu \mathrm{g} / \mathrm{kg}$, i.v.) and tyramine $(250 \mu \mathrm{g} / \mathrm{kg}$, i.v.). In this and subsequent figures, each point represents the mean of $n$ observations and the vertical line indicates the standard error of the mean. An asterisk indicates a statistically significant difference $(p<0.05)$ between the means at the indicated time.
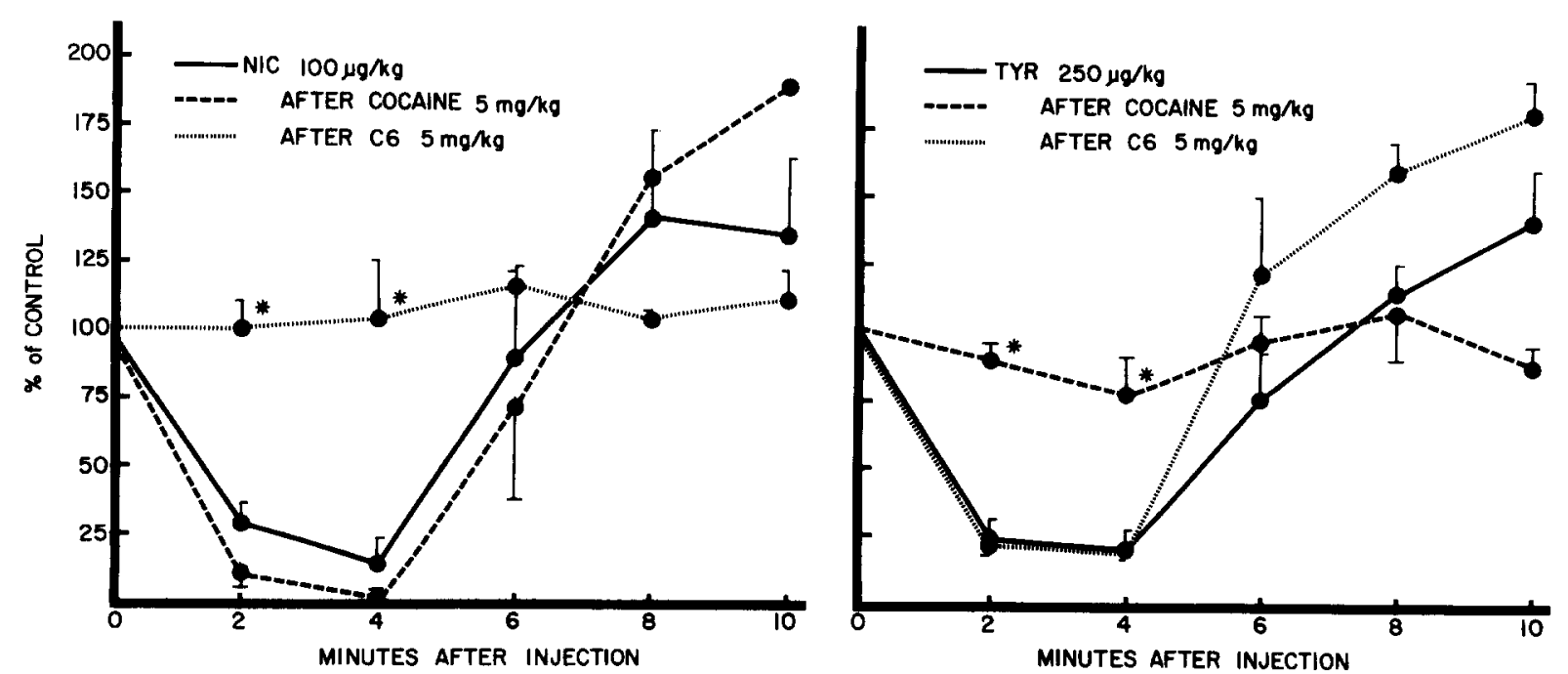

Fig. 4. Responses of the colon (CrDC-L) to nicotine and tyramine $(n=6)$ before and after cocaine $(n=3)$ or hexamethonium $(n=3)$. 

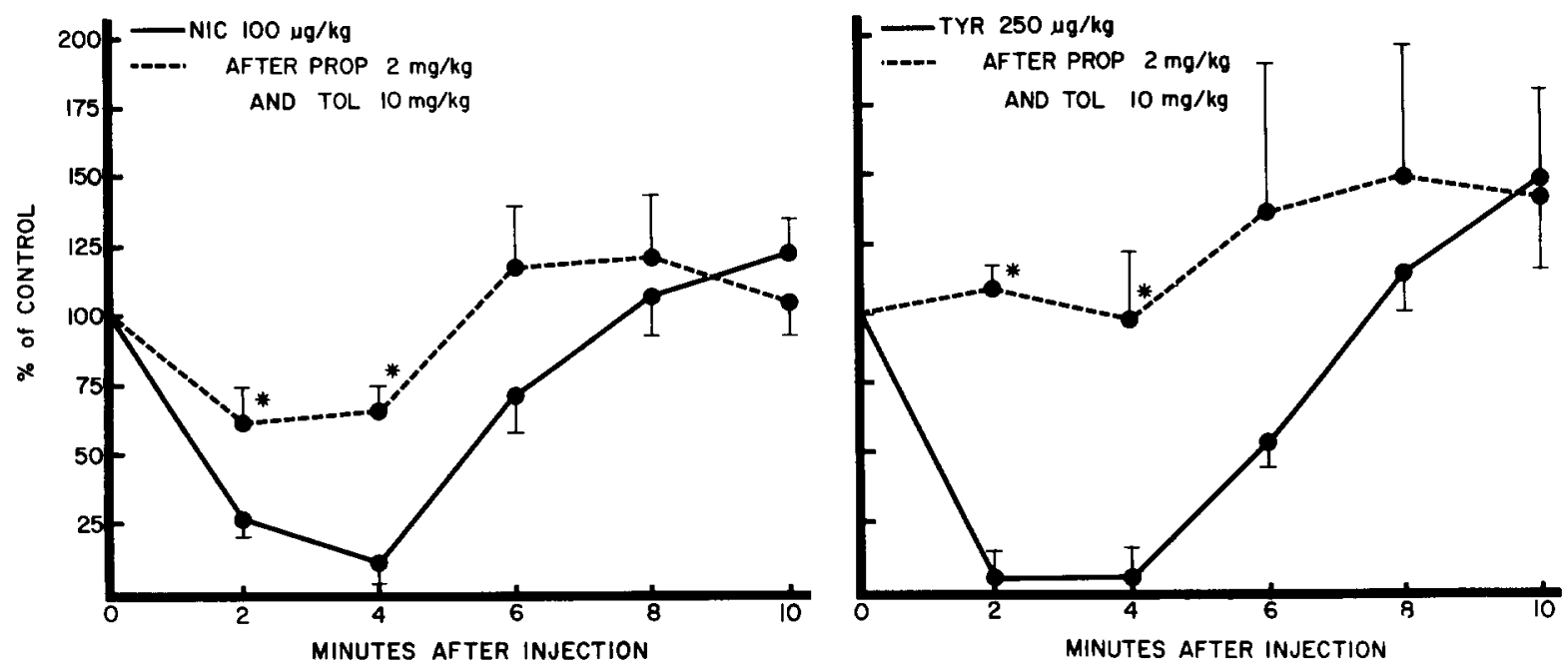

Fig. 5. Responses of the colon (CrDC-L) to nicotine $(n=4)$ or tyramine $(n=3)$ before and after propranolol (PROP) and tolazoline (TOL) in combination.
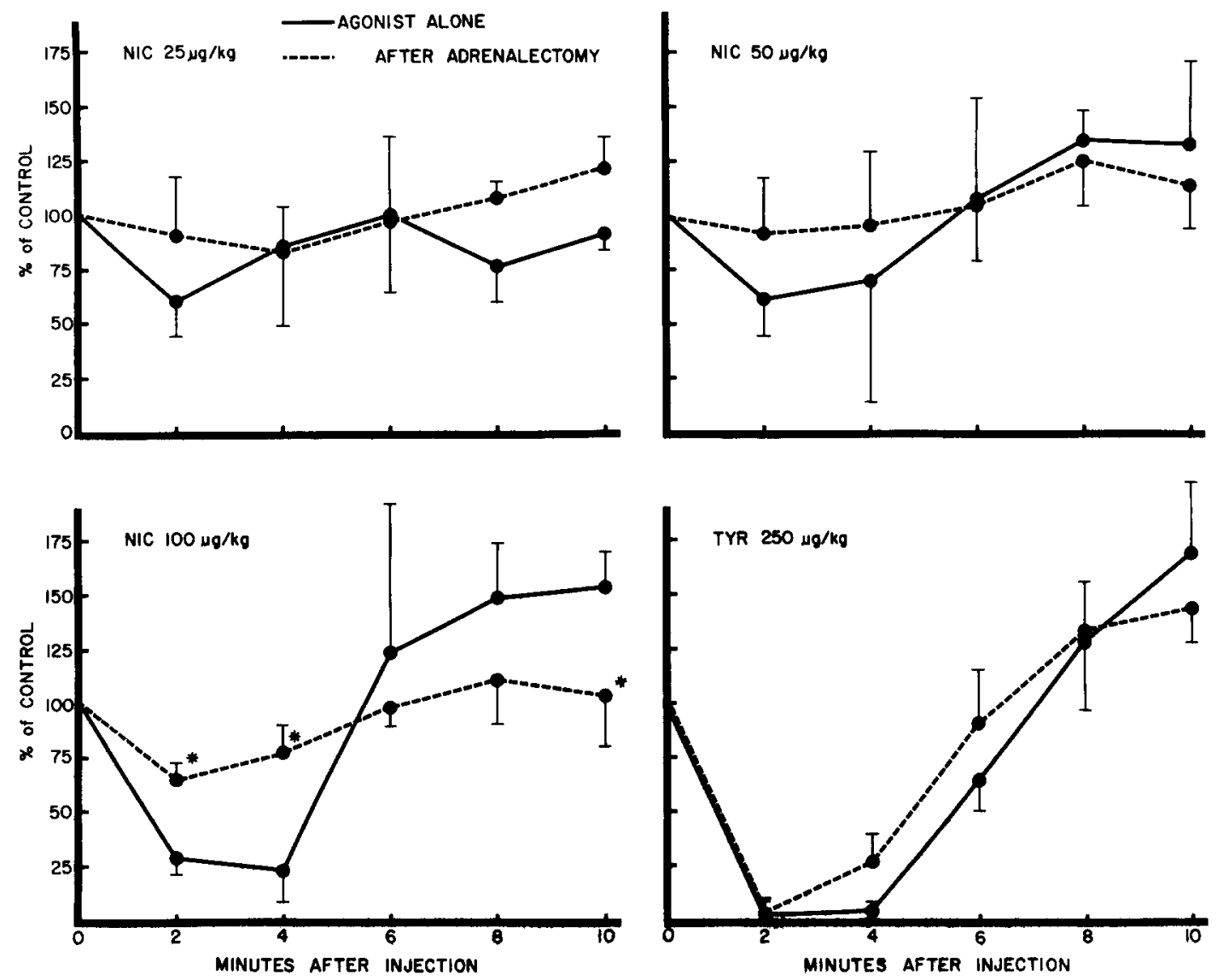

Fig. 6. Responses of the colon (CrDC-L) to nicotine (25 and $50 \mu \mathrm{g} / \mathrm{kg}, n=3 ; 100 \mu \mathrm{g} / \mathrm{kg}, n=5$ ) and tyramine ( $n=5$ ) before and after adrenalectomy. 


\subsubsection{Tolazoline and propranolol}

The combination of tolazoline, $10 \mathrm{mg} / \mathrm{kg}$, and propranolol, $2 \mathrm{mg} / \mathrm{kg}$, significantly reduced the relaxation elicited by nicotine, $100 \mu \mathrm{g} / \mathrm{kg}$, and tyramine, $250 \mu \mathrm{g} / \mathrm{kg}$ (fig. 5). The effects of 25 and $50 \mu \mathrm{g} / \mathrm{kg}$ doses of nicotine were completely blocked by the combined antagonists.

\subsubsection{Adrenalectomy}

Bilateral adrenalectomy did not alter the spontaneous contractile activity of the cranial descending colon, but it reduced both the inhibition and stimulation elicited by nicotine (fig. 6 ). The inhibitory and stimulatory responses to tyramine, $250 \mu \mathrm{g} / \mathrm{kg}$, were not altered by adrenalectomy.

\subsubsection{Reserpine pretreatment}

In reserpine-pretreated animals, nicotine, $25 \mu \mathrm{g} / \mathrm{kg}$,
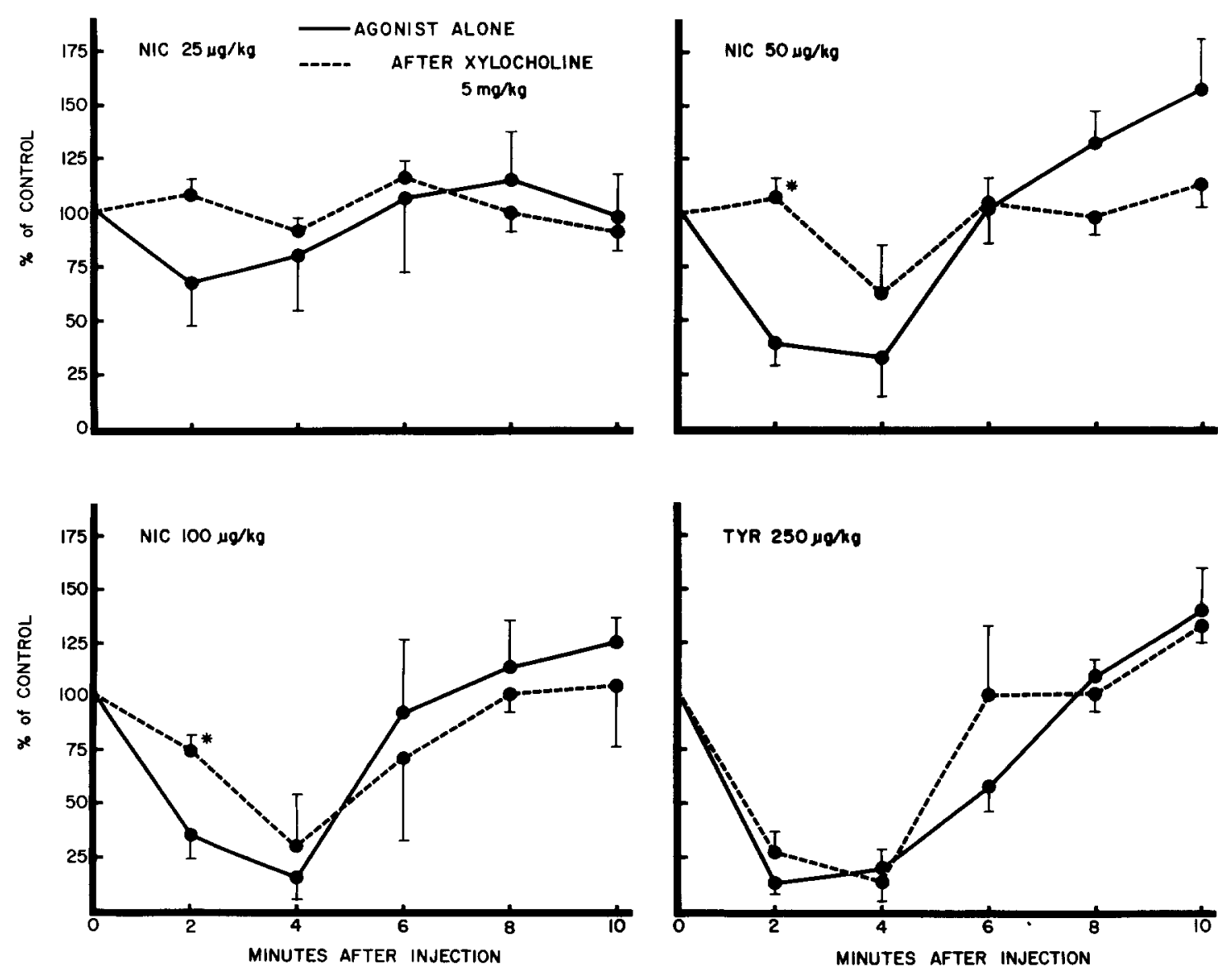

Fig. 7. Responses of the colon (CrDC-L) to nicotine and tyramine $(n=3)$ before and after xylocholine.

elicited a stimulation rather than an inhibition of contractile activity (fig. 3). The colonic responses to nicotine (50 and $100 \mu \mathrm{g} / \mathrm{kg}$ ) in the reserpine-pretreated animals were complex. During the first 2 min period after nicotine there was either a stimulation or no change in contractile activity; during the 2-4 min period, an inhibitory effect was seen. For the $100 \mu \mathrm{g} / \mathrm{kg}$ dose of nicotine, the inhibition during the 2-4 min period was as great as that in the untreated animals and the usual stimulation was seen during the $6-8$ and $8-10 \mathrm{~min}$ periods after nicotine. There was no response to tyramine, $250 \mu \mathrm{g} / \mathrm{kg}$, in the reserpine-pretreated animals (fig. 3 ).

Bilateral adrenalectomy was performed on the reserpine-pretreated animals. This procedure caused a marked drop in blood pressure. In two of the animals whose blood pressures were 65 and $75 \mathrm{~mm} \mathrm{Hg}$, the administration of nicotine, $100 \mu \mathrm{g} / \mathrm{kg}$, no longer

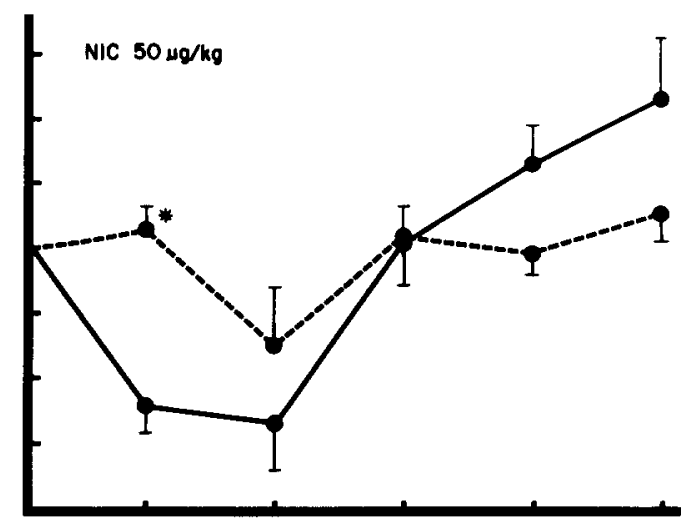


produced inhibition of contractile activity in any of the time periods.

\subsubsection{Xylocholine}

The effects of xylocholine, $5 \mathrm{mg} / \mathrm{kg}$, on the responses to the 50 and $100 \mu \mathrm{g} / \mathrm{kg}$ doses of nicotine were similar to the effects of reserpine pretreatment. That is, xylocholine reduced the relaxation during the first $2 \mathrm{~min}$ period after nicotine and had little or no effect on the relaxation during the $2-4 \mathrm{~min}$ period (fig. 7). Xylocholine administration had no effect on the responses to ty ramine, $250 \mu \mathrm{g} / \mathrm{kg}$.

Bilateral adrenalectomy was performed on two of the xylocholine-pretreated animals. In these animals, the inhibitory response to nicotine $100 \mu \mathrm{g} / \mathrm{kg}$ was abolished. Tyramine, $250 \mu \mathrm{g} / \mathrm{kg}$, however, still produced a marked inhibition of contractile activity.

\section{DISCUSSION}

The patterns of colonic contractile activity recorded during the control periods were similar to those reported for the dog by Templeton and Lawson (1931). They observed that in animals under ether anesthesia, colonic longitudinal muscle exhibited strong, fairly continuous activity (measured by the 'tandem-balloon' technique). Activity of the circular muscle was usually weak. This differential activity of the longitudinal and circular muscle was also observed in the gastric antrum and duodenum of the anesthetized dog (Carlson et al., 1970b).

The contractile activity of the colon differed from that of the upper gastrointestinal tract in that no consistent rate of contraction was observed for the colon. Contractions of the upper gastrointestinal tract are correlated with a definite, regular electrical event termed the basic electric rhythm (BER) (Bass and Wiley, 1965). The BER originates in the longitudinal muscle layer of the intestine and determines the rate of muscle contraction. To date, the BER has not been recorded from the colon of any intact animal, although an electrical event similar to the BER has been recorded from isolated circular muscle of the colon in the cat and opossum (Christensen et al., 1969). Thus, the variability in contractile rate and wave form in the colon may reflect a lack of a regulating electrical event in the longitudinal muscle.
The fact that both norepinephrine and isoproterenol relaxed the colon is consistent with the concept that both alpha- and beta-adrenergic receptor stimulants relax gastrointestinal smooth muscle (Ahlquist and Levy, 1959; Daniel, 1968; Weisbrodt et al., 1969a). The results do not agree with Templeton and Lawson (1932) who found that 'adrenalin' stimulated both the longitudinal and circular muscle layers of the colon.

The relaxation induced by nicotine appeared to be mediated via the adrenergic nervous system since the relaxation was partially antagonized by alpha- and beta-adrenergic receptor blocking agents. Impairment of the function of the adrenergic nervous system by other means also antagonized the effects of nicotine. Reserpine (Carlsson, 1957; Zamis, 1964) and xylocholine (Exley, 1957), as used in this study, would be expected to impair the function of peripheral adrenergic nerves but have little or no effect on catecholamine release from the adrenal medulla. Since both agents blocked only the early phase of inhibition by nicotine, we suggest that the initial response to nicotine is mediated by peripheral adrenergic nerves. Adrenalectomy alone reduced, and in combination with reserpine or xylocholine completely prevented the inhibitory action of nicotine. Therefore, nicotine-induced relaxation of the colon is also mediated by catecholamines released from the adrenal glands. Catecholamines from peripheral adrenergic nerves and from the adrenal medulla are responsible also for the inhibitory effects of nicotine on the upper gastroin-testinal tract (Carlson et al., 1970a, b).

The responses to nicotine were antagonized by hexamethonium, but this does not necessarily mean that nicotine was acting directly on autonomic ganglia and the adrenal medulla. Other sites of nicotine action for releasing catecholamines to inhibit contractile activity of the gut have been proposed by Carlson et al. (1970a and b). These include afferent neuronal structures and sites within the central nervous system. Hexamethonium may act on autonomic ganglia to interrupt the efferent pathways; and it may inhibit nicotine action directly in tissues devoid of autonomic ganglia (e.g., sensory nerve endings - Douglas and Gray, 1953; the ganglion-free nictitating membrane - Thompson, 1958).

Tyramine is a sympathomimetic agent which 
releases catecholamines from nerve endings but not from the adrenal glands in the intact animal (Robinson, 1966). The effects of tyramine on colonic contractile activity can be attributed to the release of catecholamines from adrenergic nerves, since these effects were blocked by the combination of alphaand beta-blocking agents, by reserpine, and by cocaine. These effects were not antagonized by adrenalectomy or by pretreatment with hexamethonium or with xylocholine. The latter procedures would not be expected to interfere with the actions of tyramine on the nerve endings (Furchgott et al., 1963). The tyramine study further confirmed that a drug which releases catecholamines from nerve endings can cause relaxation of the colon.

The qualitative effects of nicotine on the cranial descending colon were similar to those reported by Carlson et al. (1970b) for the canine gastric antrum and duodenum, that is, an initial inhibition of activity followed by a slight stimulation. Since decreased contractile activity of both the small (Gregory, 1950; Weisbrodt et al., 1969b) and large (Connell, 1962) intestine has been correlated with enhanced movement of material through the intestinal tract, the urge to defecate after smoking may be due to the inhibitory effects of nicotine on the gastrointestinal tract. This hypothesis awaits further elucidation by study of the actual transit times in the gastrointestinal tract inhibited by nicotine. The only stimulating action of nicotine was in the caudal descending colon. This response has been associated with defecation in the dog (see fig. 11 in Reinke et al., 1967). Although the increased activity produced by nicotine in the terminal colon did not cause defecation in anesthetized animals, it may have been sufficiently forceful in unanesthetized animals to cause the defecation which was reported by Carlson et al. (1970a).

\section{REFERENCES}

Ahlquist, R.P. and B. Levy, 1959, Adrenergic receptive mechanism of canine ileum, J. Pharmacol. Exptl. Therap. $127,146$.

Bass, P. and J.N. Wiley, 1965, Electrical and extraluminal contractile-force activity of the duodenum of the dog, Am. J. Digestive Diseases 10, 183.

Bayliss, W.M. and E.H. Starling, 1899, The movements and innervation of the small intestine, J. Physiol. 24, 99.
Behrman, S.J. and W. Burchfield, 1968, The intrauterine contraceptive device and myometrial activity, Am. J. Obst. Gynec. 100, 194.

Callantine, M.R., O.P. O'Brien, B.L.Windsor and R.J. Brown, 1967, Inhibition of uterine contractions in vivo in the unanesthetized rabbit, Nature 213, 507 .

Callantine, M.R., O.P. O'Brien and L.E. Clemens, 1969 , Action of an estrogen antagonist on contractility of the fallopian tube, Am. J. Physiol. 216, 1236.

Carlson, G.M., 1969, Effects of nicotine upon gastric antral and duodenal contractile activity in the dog, Doctoral Dissertation, University of Michigan, Ann Arbor, Michigan.

Carlson, G.M., R.W. Ruddon, C.C. Hug, Jr., and P. Bass, $1970 \mathrm{a}$, Effects of nicotine on gastric antral and duodenal contractile activity in the dog, J. Pharmacol. Exptl. Therap. 172, 367 .

Carlson, G.M., R.W. Ruddon, C.C. Hug, Jr., S.K. Schmiege and $P$. Bass, $1970 \mathrm{~b}$, Analysis of the site of nicotine action on gastric antral and duodenal contractile activity, J. Pharmacol. Exptl. Therap. 172, 377.

Carlsson, A., 1957, Effect of reserpine on the metabolism of catecholamines. In: Psychotropic Drugs, eds. S. Garattini and V. Chetti (Elsevier, Amsterdam).

Christensen, J., R. Caprilli and G.F. Lund, 1969, Electric slow waves in circular muscle of cat colon, Am. J. Physiol. 217,771

Connell, A.M., 1962, The motility of the pelvic colon. II-Paradoxical motility in diarrhoea and constipation, Gut 3,342 .

Daniel, E.E., 1968, Pharmacology of the gastrointestinal tract, in: Handbook of Physiology, section 6, Alimentary Canal, Vol. 4, Motility, ed. C.F. Code (Williams and Wilkins, Baltimore), p. 2267.

Douglas, W.W. and J.A.B. Gray, 1953, The excitant action of acetylcholine and other substances on cutaneous sensory pathways and its prevention by hexamethonium and d-tubocurarine, J. Physiol. 119, 118.

Exley, K.A., 1957, The blocking action of choline-2,6-xylyl ether bromide on adrenergic nerves, Brit. J. Pharmacol. 12,297

Furchgott, R.F., S.M. Kirpekar, M. Ricker and A. Schwab, 1963, Actions and interactions of norepinephrine, tyramine and cocaine on aortic strips of rabbit and left atria of guinea-pig and cat, J. Pharmacol. Exptl. Therap. $142,39$.

Gregory, R.A., 1950, Some factors influencing the passage of fluid through intestinal loops in dogs, J. Physiol. 111, 119.

Hamet, R., 1930, Action de la nicotine sur l'intestine in situ, Arch. Intern. Pharmacodyn. 38, 382.

Houssay, B.A. and E.A. Molinelli, 1926, Effect of nicotine, cytosin, lobelin, conin, piperidin and quanternary ammonias on adrenal secretion, Am. J. Physiol. 76, 551.

Jacoby, H.I., P. Bass and D.R. Bennett, 1963, In vivo extraluminal contractile force transducer for gastrointestinal muscle, J. Appl. Physiol. 18, 658. 
Larson, P.S., H.B. Haag and H. Silvette, 1961, Tobacco, Experimental and Clinical Studies (Williams and Wilkins, Baltimore).

Mulinos, M.G., 1927-28, Gastrointestinal motor responses to vagus stimulation after nicotine, Proc. Soc. Exptl. Biol. $25,49$.

Reinke, D.A., A.H. Rosenbaum, D.R. Bennett, 1967, Patterns of dog gastrointestinal contractile activity monitored in vivo with extraluminal force transducers, Am. J. Digestive Diseases 12, 113.

Robinson, R., 1966, Stimulation of the release of catecholamines from isolated adrenal glands by tyramine, $\mathrm{J}$. Pharmacol. Exptl. Therap. 151, 55.

Schnedorf, J.G. and A.C. Ivy, 1939, The effect of tobacco smoking on the alimentary tract, J.A.M.A. 112, 898.

Smoking and Health, 1964 Report of the advisory committee to the surgeon general of the public health service (Public Health Service Publication No. 1103, Washington).

Templeton, R.D. and H. Lawson, 1931, Studies in the motor activity of the large intestine. 1) Normal motility in the dog, recorded by the tandem balloon method, Am. J. Physiol. 96, 667.

Templeton, R.D. and H. Lawson, 1932, Studies in the motor activity of the large intestine, IV. Responses to autonomic drugs, Am. J. Phy siol. 101, 511.

Thompson, J.W., 1958, Studies on the response of the isolated nictitating membrane of the cat, J. Physiol. 141, 46.

Volle, R.L. and G.B. Koelle, 1970, Ganglionic stimulating and blocking agents, in: The Pharmacological Basis of Therapeutics, eds. L.S. Goodman and A. Gilman (Macmillan, New York) p. 589.

Weisbrodt, N.W., C.C. Hug, Jr. and P. Bass, 1969a, Separation of the effects of alpha- and beta-adrenergic receptor stimulation on taenia coli, J. Pharmacol. Exptl. Therap. $170,272$.

Weisbrodt, N.W., J.N. Wiley, B.F. Overholt and P. Bass, $1969 \mathrm{~b}$, A relation between gastroduodenal muscle contractions and gastric emptying, Gut 10, 543.

Zamis, E., 1964, Pharmacology of the autonomic nervous system, Ann. Rev. Pharmacol. 4, 365. 